https://dx.doi.org/10.4314/ijs.v20i2.20

Ife Journal of Science vol. 20, no. 2 (2018)

\title{
NEUROPROTECTIVE POTENTIAL OF PHENOLIC EXTRACTS OF Capsicum frutescens AS AN INHIBITOR OF MONOAMINE OXIDASE AND CHOLINESTERASE ACTIVITIES
}

\author{
Ogunruku, O. O. ${ }^{a^{*}}$, Oboh, G. ${ }^{b}$ and Ogunsuyi, O. B. ${ }^{b}$ \\ ${ }^{a}$ Department of Biochemistry and Molecular Biology, Obafemi Awolowo University, Ile-Ife, Nigeria. \\ ${ }^{b}$ Functional Food and Nutraceutical Unit, Department of Biochemistry, Federal University of Technology, Akure, Ondo \\ State, Nigeria. \\ *Corresponding author's email address: omodesola.oluwafisayo@gmail.com; Tel.: +234 8092083337
}

(Received: 30 May, 2018; Accepted: 29 June, 2018)

ABSTRACT

\begin{abstract}
In this study, we investigated the in vitro antioxidant activity of the extracts from ripe and unripe fruits of Capsicum frutescens. The effects of the extracts on three enzymes which are associated with Parkinson's disease (PD) were also investigated together with quantitation of total phenol, flavonoid and non-flavonoid contents of the extracts. Activities of mitochondrial monoamine oxidase (MAO), acetylcholinesterase (AChE) and butyrylcholinesterase (BChE) from rat brain were determined in the presence of the extracts. 1, 1-diphenyl-2picrylhydrazyl (DPPH) and OH radicals scavenging abilities, as well as membrane stabilizing effect of the extract via inhibition of $\mathrm{Fe}^{2+}$-induced lipid peroxidation in rat brain tissue homogenate were assessed. The results revealed that the extracts exhibited mitochondrial $\mathrm{MAO}, \mathrm{AChE}$ and $\mathrm{BChE}$ inhibitory effects in concentrationdependent manner, with the unripe fruit extract showing significantly higher $(\mathrm{P}<0.05)$ inhibitory effects than the ripe fruit extract. However, the ripe fruit extract had significantly higher total phenol and flavonoid contents, as well as exhibited significantly higher $(\mathrm{P}<0.05) \mathrm{DPPH}$ free radical scavenging and membrane stabilizing effects. The observed antioxidant and enzyme inhibitory properties of ripe and unripe pepper (C. frutescens) fruits extracts could be an interplay among their constituent polyphenols. This could be a justification for their use as nutraceutical/dietary intervention in the management of neurodegenerative diseases, especially PD. Collectively, these findings suggest that $C$. frutescens could serve as a functional food/nutraceutical in the management of PD and our further studies will be directed towards characterization of the biomolecules involved and their mechanism(s) of action in appropriate models.
\end{abstract}

Key words: Monoamine oxidase, Cholinesterases, Capsicum spp, Neurodegenerative diseases, Functional foods.

\section{INTRODUCTION}

Parkinson's disease (PD) ranks the most common neurodegenerative movement disorder in the world (Tamilselvam et al., 2013). This pathology is often characterized by a gradual but progressive loss of dopaminergic neurons in the substantia nigra pars compactra (SNpc) as well as aggregation of proteinaceous cytoplasmic inclusions called Lewy bodies (Soldner et al., 2009). Several experimental reports have shown that the loss of dopaminergic neurons in PD is as a result of multiple pathological mechanisms including oxidative stress, mitochondria dysfunction, aggregation and accumulation of misfolded or damaged proteins, impaired calcium homeostasis, excitotoxicity, and accumulation of iron (Tamilselvam et al., 2013). These impairments result in Parkinson-like symptoms characteristic of $\mathrm{PD}$, which includes bradykinesia, resting tremors, postural instability and muscular rigidity
(Moore et al., 2005). Risk factors for the development of PD include genetic mutation of several genes, such as parkin (Cookson and Bandman, 2010); inflammation and exposure to various environmental toxicants (Angeline et al., 2012). Current therapeutic measures available for the management of PD include the conservation of neuronal dopamine via monoamine oxidase inhibitors, the reduction in PD-induced oxidative stress via antioxidant therapy and symptomatic reduction in PD-associated dementia via the use of cholinesterase inhibitors.

Despite the successes recorded in the development of therapeutic drugs such as monoamine oxidase (MAO) inhibitors for the management of Parkinson's disease (PD), the attendant side effects and huge financial burden they come with has intensified research interest into natural therapeutic measures. In view of this, 
plant phenolic extracts have received enormous research attention as one of the most promising phytochemicals with neuroprotective properties. In one study, Sloley et al. (2000) reported kaempferol as a MAO inhibitor and potential neuroprotectant in extracts of Ginkgo biloba leaves. Also, Akinyemi et al. (2016) reported the neuroprotectitve properties of diets supplemented with the phenolic-rich rhizomes of ginger and turmeric in hypertensive rats; while Oboh et al. (2016) reported the potential neuroprotective properties of phenolic extract from Heinsia crinita leaves as exhibiting antioxidant as well as monoamine oxidase and cholinesterase properties in vitro.

Pepper (Capsicum frutescens) fruit belongs to the genus Capsicum which includes a varying species of spices known for their nutritional and medicinal properties (Jolayemi and Ojewole, 2013). In folklore medicine, C. frutescens fruit, along with other Capsicum species have been used in the treatment of different diseases including diarrhoea, asthma, arthritis, muscle cramps and toothache (Jolayemi and Ojewole, 2013). In addition, $C$. frutescens fruits have been reported for their antimicrobial, antioxidant and antihyperglycemic properties (Khan et al., 2013). In this study, we investigated the in vitro antioxidant properties and inhibitory effect of phenolic extracts from ripe and unripe pepper fruits on some enzymes (mitochondrial monoamine oxidase, acetylcholinesterase and butyrylcholinesterase) that are linked to PD. This is in a bid to evaluating the potentials of $C$. frutescens fruit as a nutraceutical/dietary intervention in the management of neurodegenerative diseases such as PD.

\section{MATERIALS AND METHODS}

\section{Materials}

\section{Sample Collection and Preparation}

The ripe and unripe fruits of pepper (Capsicum frutescens), locally referred to as 'ata wewe') were obtained from farm settlements around Iboropa Akoko, Ondo State, Nigeria. Identification was carried out at the Department of Botany, Obafemi Awolowo University, Ile-Ife, Nigeria. The fruits were washed and thereafter lyophilized.
Lyophilized samples were then pulverized and kept for subsequent studies.

\section{Chemicals}

Thiobarbituric acid (TBA), 2-deoxyribose, gallic, quercetin, Folin-Ciocalteau's reagent, acetylthiocholine iodide, butyrylcholine iodide, mannitol, benzylamine, semicarbazide, EDTA, sodium dodecyl sulphate (SDS), 1, 1-diphenyl-2picrylhydrazyl (DPPH), trizma base were procured from Sigma-Aldrich, Inc., (St Louis, MO, USA). Trichloroacetic acid (TCA) and sodium carbonate were sourced from SigmaAldrich, Chemie GmbH (Steinheim, Germany). Hydrochloric acid, hydrogen peroxide, benzene, sodium dihydrogen phosphate, disodium hydrogen phosphate, methanol and acetic acid were procured from Scharlab SL, Spain. Aluminum chloride, potassium acetate, iron (II) sulfate, potassium ferricyanide and ferric chloride were sourced from BDH Chemicals Ltd., (Poole, England). Except otherwise stated, water was glass distilled and all other chemicals and reagents were of analytical grade.

\section{Methods}

\section{Extraction of Polyphenols}

Pepper fruits (ripe and unripe Capsicum frutescens) were extracted with 20 volumes of acidified methanol for 48 hours, and thereafter filtered through cheese cloth. The filtrate was reduced under pressure until about $90 \%$ of the solvent was evaporated and thereafter lyophilized and stored at $-40{ }^{\circ} \mathrm{C}$ until further analysis (Oboh and Ogunruku, 2010).

\section{Determination of Inhibitory effect of $C$. frutescens on Mitochondrial Monoamine Oxidase Activity}

\section{Preparation of Mitochondria}

The rats were immobilized via cervical dislocation and whole brain were quickly excised, placed on ice and weighed. Isolation of brain mitochondria was carried out according to previously reported methods (Satav and Katyare, 1982, Gacche et al., 2011). Whole brain was homogenized in $20 \mathrm{ml}$ of buffer containing $0.3 \mathrm{M}$ mannitol and $0.1 \mathrm{mM}$ EDTA, pH 7.4. The homogenate was centrifuged at $600 \mathrm{x} g$ for $10 \mathrm{~min}$ at $4{ }^{\circ} \mathrm{C}$. The supernatant was 
collected and centrifuged further at 10,000 x $\mathrm{g}$ for 10 min at $4{ }^{\circ} \mathrm{C}$ to obtain the brain mitochondria. The mitochondria pellets thus obtained were washed once with $0.25 \mathrm{M}$ sucrose solution containing $0.1 \mathrm{M}$ EDTA, re-suspended in $0.25 \mathrm{M}$ sucrose solution and stored at $4{ }^{\circ} \mathrm{C}$ for further studies. Protein concentration was determined based on a modified method of Lowry et al. (1951).

\section{Monoamine Oxidase Activity}

Monoamine oxidase (MAO) activity of the rat brain mitochondria was determined based on a previously reported method (Green and Haughton, 1961). The reaction mixture contained $25 \mathrm{mM}$ phosphate buffer $\mathrm{pH} 7,12.5 \mathrm{mM}$ semicarbazide, $10 \mathrm{mM}$ benzylamine $(\mathrm{pH} 7), 0.2$ $\mathrm{mg}$ brain mitochondria isolate and pepper extract $(0-120 \mu \mathrm{g} / \mathrm{ml})$ in a total reaction mixture of $1 \mathrm{ml}$. After $30 \mathrm{~min}, 1 \mathrm{ml}$ of acetic acid was added. The mixture was boiled for $3 \mathrm{~min}$ and centrifuged at $1000 \mathrm{rpm}$ for $5 \mathrm{~min}$. The supernatant $(0.75 \mathrm{ml})$ obtained was mixed with equal volume of $0.05 \%$ 2,4-dinitrophenylhydrazine (DNPH) and $2 \mathrm{ml}$ of benzene was added after $10 \mathrm{~min}$ incubation at room temperature. The separated benzene layer obtained was thereafter mixed with an equal volume of $0.1 \mathrm{M} \mathrm{NaOH}$. The alkaline layer was decanted and heated at $80{ }^{\circ} \mathrm{C}$ for $10 \mathrm{~min}$. The orange-yellow colour was measured spectrophotometrically at $450 \mathrm{~nm}$. MAO inhibitory activity of the $C$. frutescens extracts were expressed as percentage inhibition with reference to the control which did not contain the inhibitor.

\section{Determination of Cholinesterases activity in vitro}

The acetylcholinesterase (AChE) activity was determined according to the method of Ellman et al. (1961). The rats were immobilized via cervical dislocation and whole brain were quickly dissected, placed on ice and weighed. The brain was removed, placed on ice and was homogenized in 10 volumes of $0.1 \mathrm{M}$ phosphate buffer, $\mathrm{pH}$ 7.0. The homogenate was centrifuged at $4000 \mathrm{rpm}$ for 5 min to yield a low-speed supernatant, which was used for the assay. The reaction mixture contained $200 \mu \mathrm{l}$ of the low-speed supernatant, $100 \mu \mathrm{l}$ of a solution of 5, 5-dithiobis-(2-nitrobenzoic) acid (3.3 mM DTNB and $6 \mathrm{mM} \mathrm{NaHCO}$ in $0.1 \mathrm{M}$ phosphate buffer, $\mathrm{pH} 7.0), 10 \mathrm{mg} / \mathrm{ml}$ pepper extracts $(20-100 \mu l)$ and $500 \mu l$ of $0.1 \mathrm{M}$ phosphate buffer ( $\mathrm{pH}$ 8.0). After incubation for $20 \mathrm{~min}$ at 25 ${ }^{\circ} \mathrm{C}, 5 \mathrm{mM}$ substrate (acetylthiocholine iodide/butyrylcholine iodide) was added to initiate the reaction. Enzyme activity was determined by UV-Visible spectrophotometer from the absorbance changes at $412 \mathrm{~nm}$ for $3 \mathrm{~min}$ at $20 \mathrm{~min}$ intervals. The $\mathrm{AChE}$ and $\mathrm{BuChE}$ inhibitory activities were expressed as percentage inhibition with reference to the control which did not contain the inhibitor.

\section{Lipid Peroxidation assay \\ Tissue Preparation}

The rats were immobilized via cervical dislocation and whole brain were quickly dissected, placed on ice and weighed. The tissue was subsequently homogenized in cold saline $(1 / 10 \mathrm{w} / \mathrm{v})$ with about 10-up-and-down strokes at approximately 1200 $\mathrm{rev} / \mathrm{min}$ at $4{ }^{\circ} \mathrm{C}$ in a Teflon glass homogenizer. The homogenates were centrifuged for $10 \mathrm{~min}$ at $1000 \times \mathrm{g}$ to yield a low-speed supernatant (S1) fraction that was kept for lipid peroxidation assay (Belle et al., 2004).

\section{Thiobarbituric acid (TBARS) reaction}

The lipid peroxidation assay was carried out using the modified method of Ohkawa et al. (1979). Briefly $100 \mu \mathrm{l}$ S1 fraction was mixed with a reaction mixture containing $30 \mu \mathrm{l}$ of $0.1 \mathrm{M}$ Tris$\mathrm{HCl}$ buffer ( $\mathrm{pH} 7.4)$, pepper extract $(0-100 \mu \mathrm{l})$ and $30 \mu \mathrm{l}$ of $250 \mu \mathrm{M}$ freshly prepared $\mathrm{FeSO}_{4}$. The volume was made up to $300 \mu \mathrm{l}$ by water before incubation at $37^{\circ} \mathrm{C}$ for 1 hour. The colour reaction was developed by adding $300 \mu \mathrm{l} \quad 8.1 \%$ SDS (Sodium dodecyl sulphate) to the reaction mixture containing S1, this was subsequently followed by the addition of $500 \mu \mathrm{l}$ of acetic acid/ $\mathrm{HCl}(\mathrm{pH} 3.4)$ mixture and $500 \mu \mathrm{l} 0.8 \%$ TBA (Thiobarbituric acid). This mixture was incubated at $100{ }^{\circ} \mathrm{C}$ for 1 hour. TBARS (Thiobarbituric acid reactive species) produced were measured at $532 \mathrm{~nm}$ in a spectrophotometer and the absorbance was compared with that of the standard curve prepared using malondialdehyde (MDA).

\section{Determination of DPPH Radical Scavenging Ability}

The free radical scavenging ability of the $C$. frutescens extracts against DPPH free radical was evaluated as described by Gyamfi et al. (1999). 
Briefly, appropriate dilutions of the extracts $(1 \mathrm{ml})$ were mixed with $1 \mathrm{ml} 0.4 \mathrm{mM}$ DPPH radicals in methanolic solution. The mixture was left in the dark for $30 \mathrm{~min}$, and the absorbance was taken at $516 \mathrm{~nm}$. The experimental control consisted of 2 $\mathrm{ml} \mathrm{DPPH}$ solution in the absence of test samples. The DPPH free radical scavenging ability was subsequently expressed as percentage of the control.

\section{Fenton Reaction (Inhibition of Degradation of Deoxyribose)}

The ability of the ripe and unripe $C$. frutescens extracts to prevent $\mathrm{Fe}^{2+} / \mathrm{H}_{2} \mathrm{O}_{2}$-induced decomposition of deoxyribose was carried out using the method of Halliwell and Gutteridge (1981). Briefly, appropriate dilution of the extracts was added to a reaction mixture containing $20 \mathrm{mM}$ deoxyribose $(120 \mu \mathrm{l}), 0.1 \mathrm{M}$ phosphate buffer (400 $\mu \mathrm{l}), 20 \mathrm{mM}$ hydrogen peroxide $(40 \mu \mathrm{l})$ and $500 \mu \mathrm{M}$ $\mathrm{FeSO}_{4}(40 \mu \mathrm{l})$, and the volume was made up to 800 $\mu \mathrm{l}$ with distilled water. The reaction mixture was incubated at $37^{\circ} \mathrm{C}$ for $30 \mathrm{~min}$, and the reaction was then stopped by the addition of $0.5 \mathrm{ml}$ of $2.8 \%$ trichloroacetic acid (TCA), this was followed by the addition of $0.4 \mathrm{ml}$ of $0.6 \%$ thiobarbituric acid (TBA) solution. The tubes were incubated in boiling water for $20 \mathrm{~min}$. The absorbance was read at $532 \mathrm{~nm}$ in a spectrophotometer and percentage $(\%) \mathrm{OH}$ radical scavenging ability was subsequently calculated.

\section{Determination of Total Phenol Content}

The total phenol content was determined according to the method of Singleton et al. (1999). Briefly, appropriate dilutions of $C$. frutescens extracts were oxidized with $2.5 \mathrm{ml} \mathrm{10 \%} \mathrm{Folin-}$ Ciocalteau's reagent $(\mathrm{v} / \mathrm{v})$ and neutralized with 2.0 $\mathrm{ml}$ of $7.5 \%$ sodium carbonate. The reaction mixture was incubated for $40 \mathrm{~min}$ at $45^{\circ} \mathrm{C}$ and the absorbance was measured at $765 \mathrm{~nm}$ in the spectrophotometer. The total phenol content was calculated as gallic acid equivalent.

\section{Determination of Total Favonoid Content}

The total flavonoid content of C. frutescens extracts was determined using a slightly modified method reported by Meda et al. (2005). Briefly, $0.5 \mathrm{ml}$ of appropriately diluted sample extracts were mixed with $0.5 \mathrm{ml}$ methanol, $50 \mu \mathrm{l} 10 \% \mathrm{AlCl}_{3}, 50 \mu \mathrm{l} 1 \mathrm{M}$ potassium acetate and $1.4 \mathrm{ml}$ water, and incubated at room temperature for $30 \mathrm{~min}$. The absorbance of the reaction mixture was measured at $415 \mathrm{~nm}$ and the total flavonoid content calculated as quercetin equivalent.

\section{Data Analysis}

The results of three (3) experiments were pooled and expressed as mean \pm standard deviation (SD). Mean values were appropriately analysed and compared using Student's t-test (unpaired) and significance was accepted at $\mathrm{P} \leq 0.05$. Also, $\mathrm{IC}_{50}$ (effective concentration of extract causing $50 \%$ inhibition) values were calculated using nonlinear regression analysis. All statistical analyses were carried out using GraphPad Prism version 5.0 for Windows.

\section{RESULTS}

Figure 1 shows the inhibitory effect of the extracts on the activity of monoamine oxidase from the mitochondria of rat brain tissue. As revealed, both extracts were able to inhibit $\mathrm{MAO}$ in concentration dependent manner $(0-120 \mu \mathrm{g} / \mathrm{ml})$. In table 1 showing the $\mathrm{EC}_{50}$ values, unripe extract $(52.68 \pm 0.04 \mu \mathrm{g} / \mathrm{ml})$ had a significantly $(\mathrm{P}<0.05)$ higher inhibitory effect than ripe extract $(72.05 \pm 0.02 \mu \mathrm{g} / \mathrm{ml})$. The inhibitory effects of the extracts on acetylcholinesterase (AChE) and butyrylcholinesterase (BChE) activities are shown in figures 2 and 3 . A concentration dependent (20 $-100 \mu \mathrm{g} / \mathrm{ml}$ ) inhibition of the cholinesterase activities by the extracts were observed; however, judging by the $\mathrm{EC}_{50}$ values, (Table 1), unripe extract had a significantly $(\mathrm{P}<0.05)$ higher AChE $(32.37 \pm 0.12 \mu \mathrm{g} / \mathrm{ml})$ and $\mathrm{BChE}(63.49 \pm 0.12$ $\mu \mathrm{g} / \mathrm{ml})$ inhibitory effect than the unripe extract $(\mathrm{AChE}=100.50 \pm 0.11 \mu \mathrm{g} / \mathrm{ml} ; \mathrm{BChE}=$ $79.93 \pm 0.15 \mu \mathrm{g} / \mathrm{ml})$. 


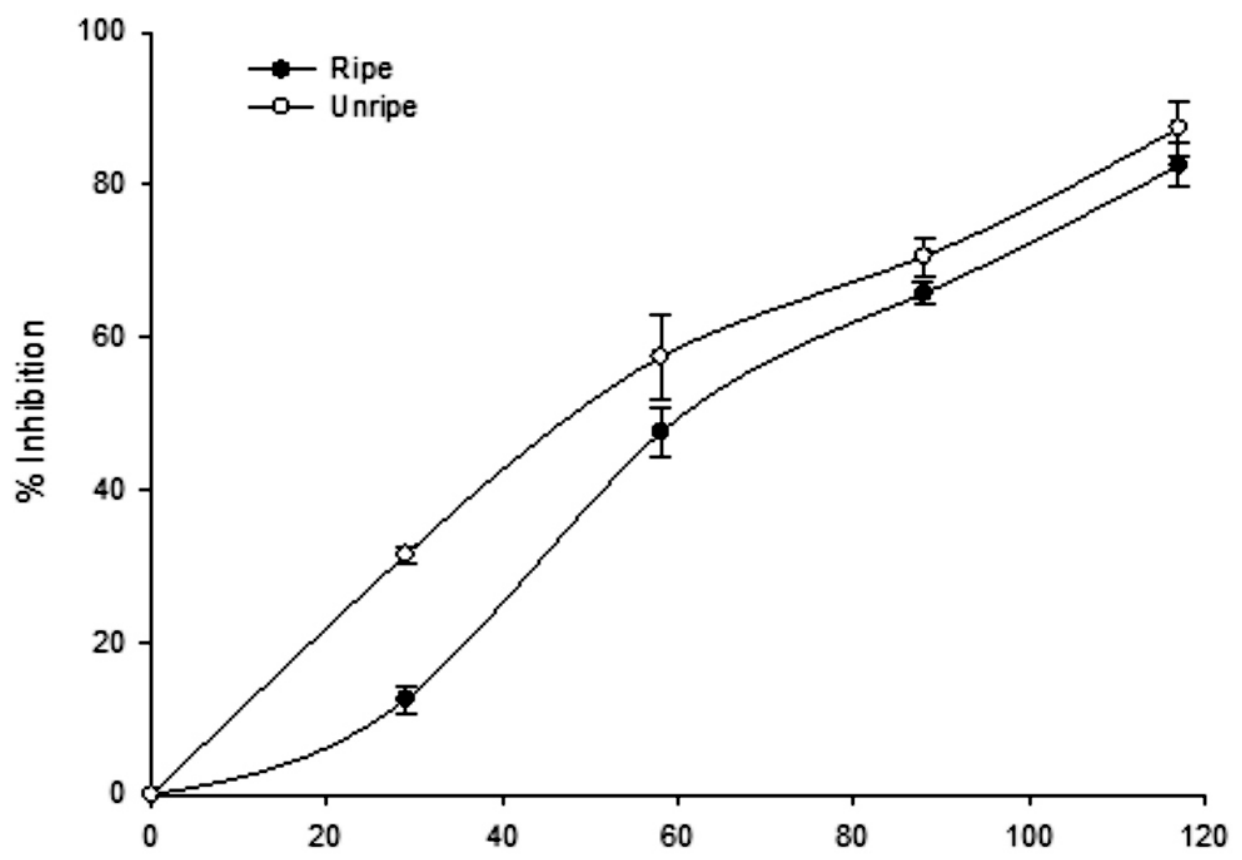

Figure 1: Percentage Inhibition of Brain Mitochondrial Monoamine Oxidase (MAO) Activity as a Function of Concentration of Phenolic Extracts from Capsicum frutescens

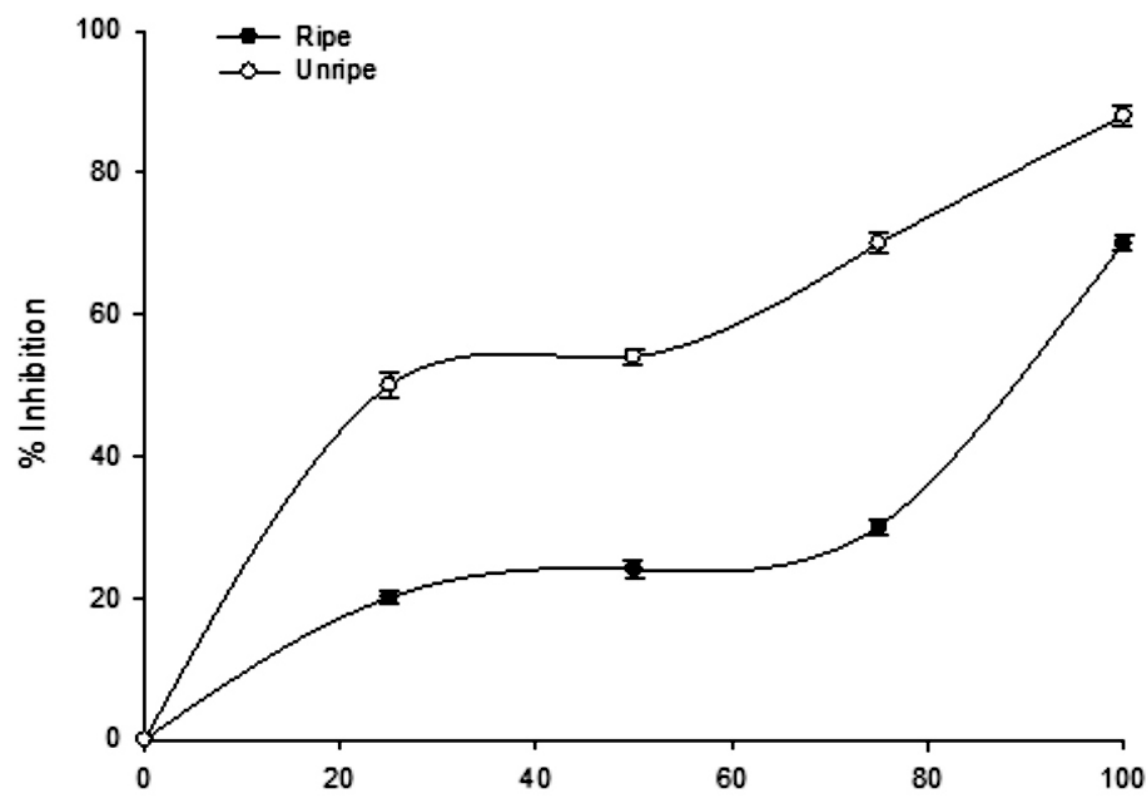

Figure 2a: Percentage Inhibition of Acetylcholinesterase Activity as a Function of Concentration of Phenolic Extracts from Capsicum frutescens 


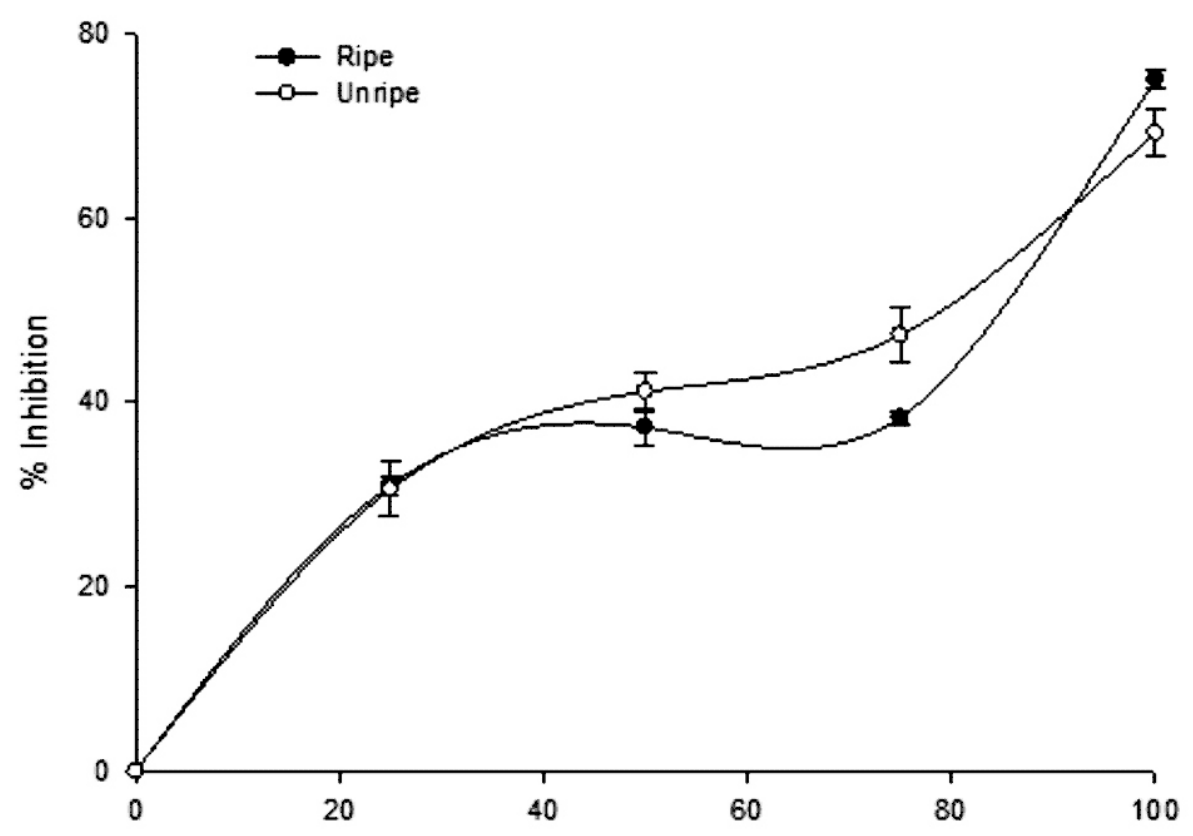

Figure 2b: Percentage Inhibition of Butyrylcholinesterase Activity as a Function of Concentration of Phenolic Extracts from Capsicum frutescens

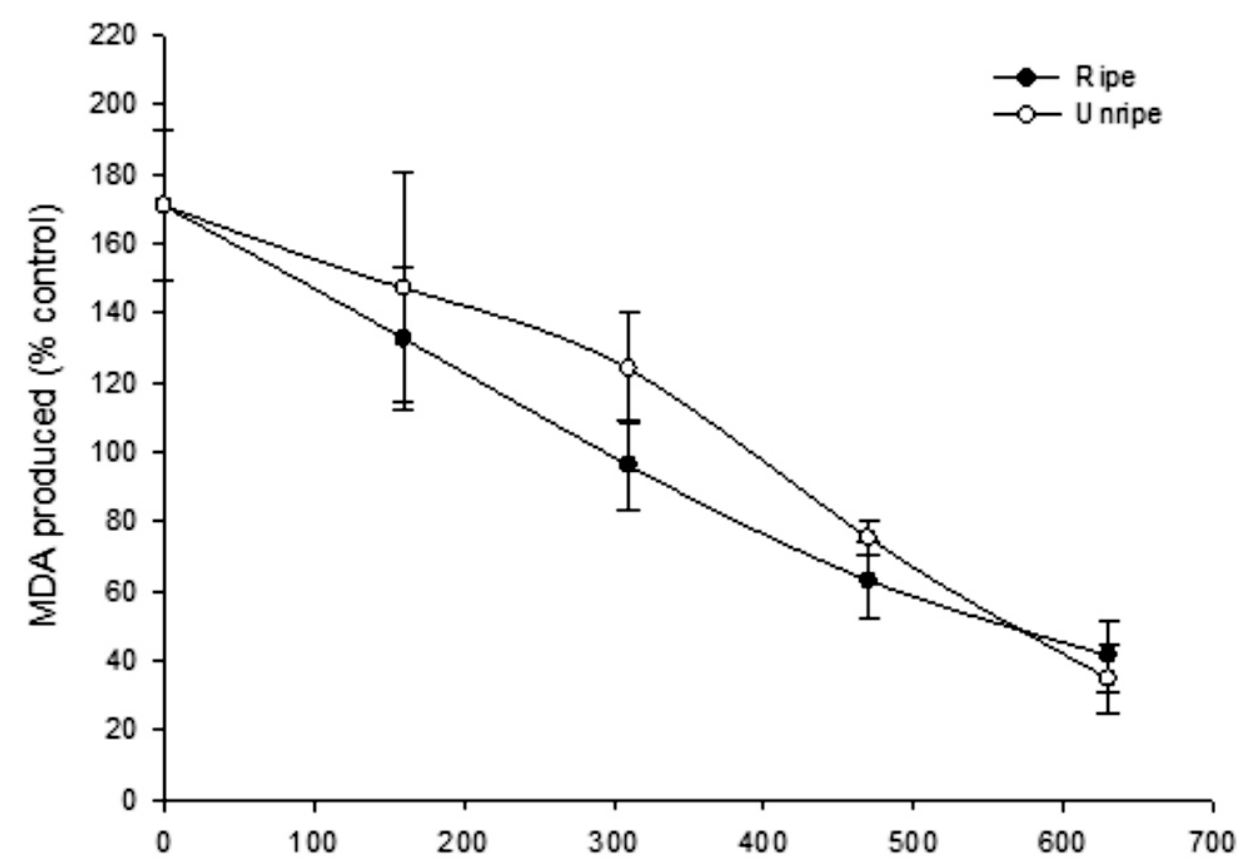

Figure 3: Inhibition of $\mathrm{Fe}^{2+}$-induced Lipid Peroxidation in Rat Brain Tissue by Phenolic Extracts from Capsicum frutescens 


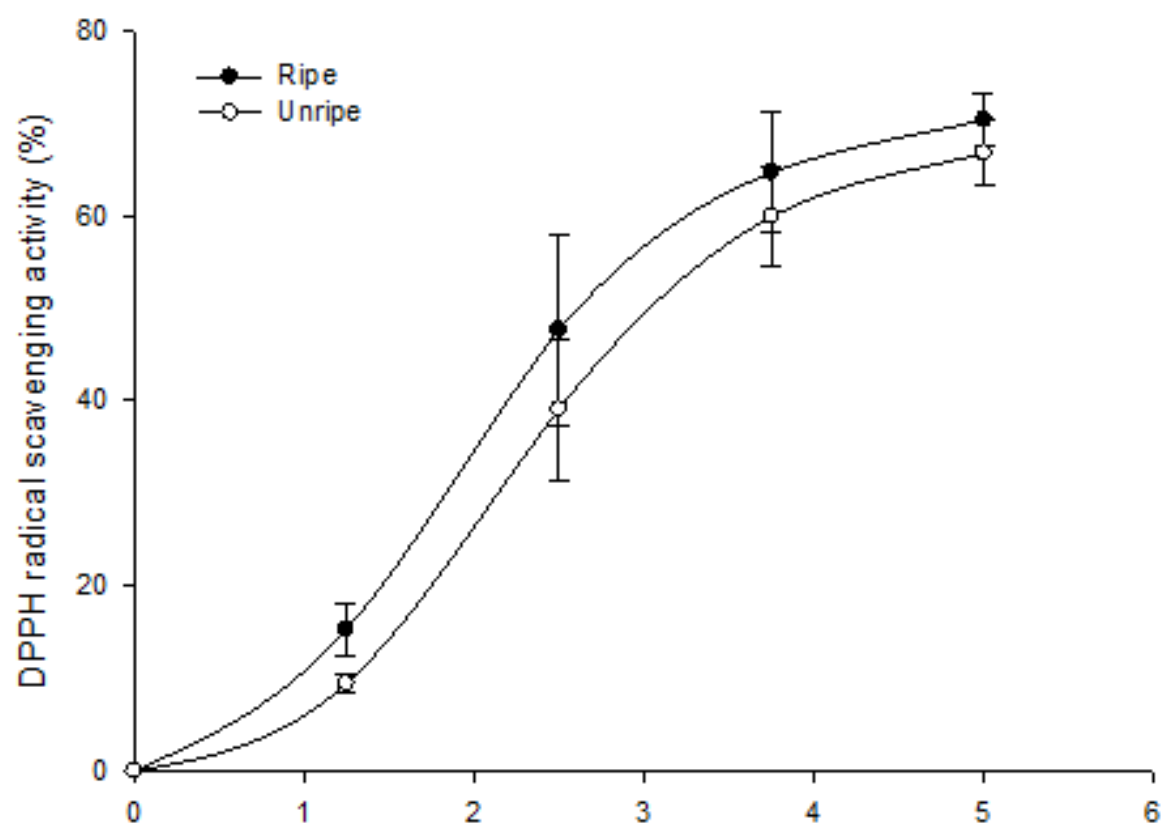

Figure 4: DPPH Radical Scavenging Ability of Phenolic Extracts from Capsicum frutescens

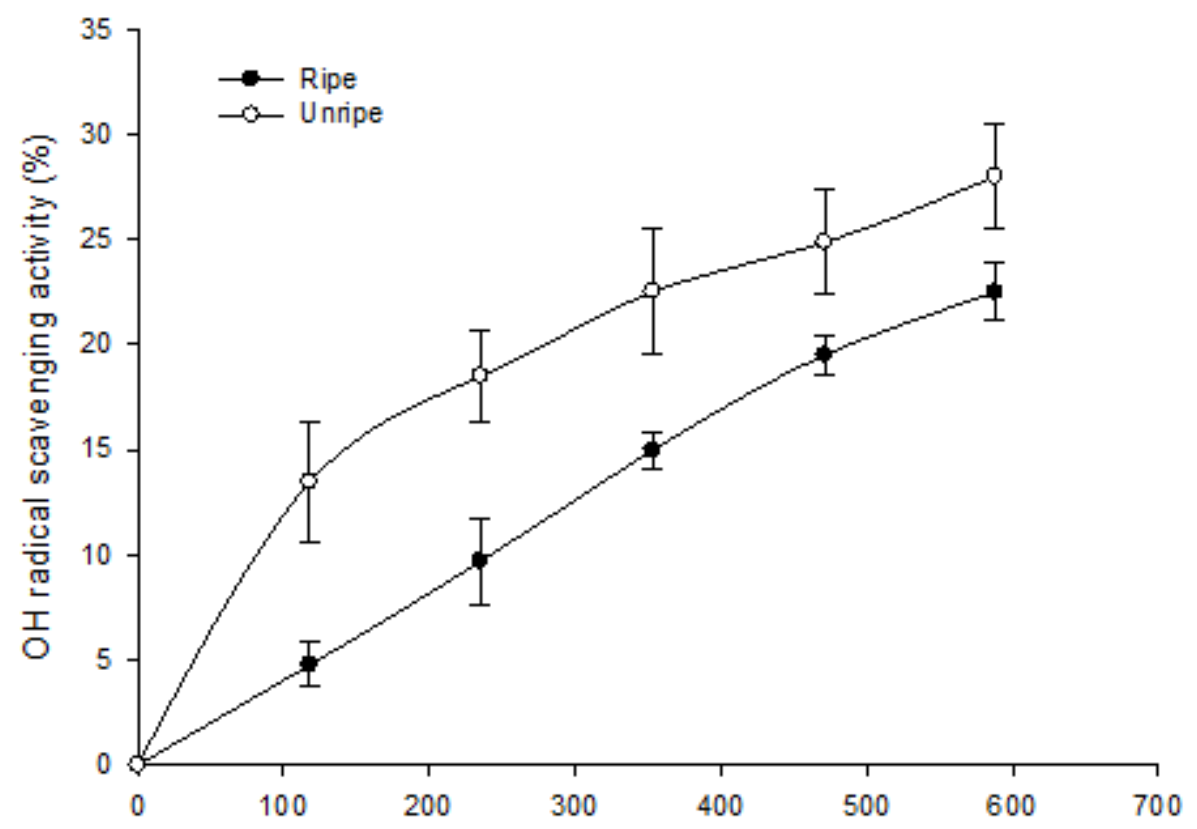

Figure 5: Hydroxyl Radical Scavenging Ability of Phenolic Extracts from Capsicum frutescens 
Table 1: $\mathrm{EC}_{50}$ Values $(\mu \mathrm{g} / \mathrm{ml})$ of Phenolic Extracts from C. frutescens.

\begin{tabular}{lrr}
\hline & \multicolumn{2}{c}{ Sample } \\
\cline { 2 - 3 } & \multicolumn{1}{c}{ Unripe } & \multicolumn{1}{c}{ Ripe } \\
\hline MAO & $52.68 \pm 0.04^{\mathrm{a}}$ & $72.05 \pm 0.02^{\mathrm{b}}$ \\
$\mathrm{AChE}$ & $32.37 \pm 0.12^{\mathrm{a}}$ & $100.50 \pm 0.11^{\mathrm{b}}$ \\
$\mathrm{BChE}$ & $63.49 \pm 0.12^{\mathrm{a}}$ & $79.93 \pm 0.15^{\mathrm{b}}$ \\
& & \\
$\mathrm{MDA}$ reduction & $377.80 \pm 1.79^{\mathrm{b}}$ & $251.20 \pm 0.78^{\mathrm{a}}$ \\
$\mathrm{DPPH}$ & $3.81 \pm 0.02^{\mathrm{b}}$ & $2.95 \pm 0.04^{\mathrm{a}}$ \\
$\mathrm{OH}$ & $131.8 \pm 0.04^{\mathrm{a}}$ & $219.0 \pm 0.03^{\mathrm{b}}$ \\
\hline
\end{tabular}

Values represent mean \pm standard deviation of triplicate experiments. Values with different superscript letters along the same row are significantly different $(\mathrm{P}<0.05)$. $\mathrm{EC}_{50}$ values were determined by non linear regression analysis of the dose- response curves. MAO-monoamine oxidase, AChE-acetylcholinesterase, BChEbutyrylcholinestase, MDA-malondialdehyde

Table 2: Total Phenol, Total Flavonoid and Non-Flavonoid Phenolic Content of Ripe and Unripe Pepper (C. frutescens) Fruits

\begin{tabular}{lll}
\hline & Unripe & Ripe \\
\hline Total Phenol* $^{*}$ & $86.04 \pm 4.16^{\mathrm{a}}$ & $90.30 \pm 3.27 \mathrm{~b}$ \\
Total Flavonoid $^{* *}$ & $52.10 \pm 0.09^{\mathrm{a}}$ & $66.67 \pm 7.86^{\mathrm{b}}$ \\
Non Flavonoid Phenolics*** & $33.94 \pm 4.16^{\mathrm{b}}$ & $23.63 \pm 11.13^{\mathrm{a}}$ \\
\hline
\end{tabular}

Values represent means \pm standard deviation of triplicate experiments Values with different superscript letters along the same row are significantly different $(\mathrm{P}<0.05)$.

*mg gallic acid equivalent (GAE) $/ 100 \mathrm{~g}$ dry weight of sample

**mg quercetin equivalent (QAE)/100 g dry weight of sample

*** mg / $100 \mathrm{~g}$ dry weight of sample

Incubation of $\mathrm{Fe}^{2+}$ with rat brain tissue homogenate resulted in a significant $(\mathrm{P}<0.05)$ increase in rat brain MDA content $(171.92 \pm 21.62 \%)$. However, both extracts significantly $(\mathrm{P}<0.05)$ reduced brain $\mathrm{MDA}$ content in a concentration $(100-700 \mu \mathrm{g} / \mathrm{ml})$ dependent manner. The $\mathrm{EC}_{50}$ values presented in table 1 showed a significant $(\mathrm{P}<0.05)$ difference in the inhibitory effect on MDA production of ripe $(251.20 \pm 0.07 \mu \mathrm{g} / \mathrm{ml})$, which is higher than the unripe $(377.80 \pm 0.03 \mu \mathrm{g} / \mathrm{ml})$ extracts.

C. frutescens extracts scavenged both DPPH and $\mathrm{OH}$ radicals in a concentration-dependent manner (1-5 $\mu \mathrm{g} / \mathrm{ml}$ and $100-600 \mu \mathrm{g} / \mathrm{ml}$ respectively). According to the $\mathrm{EC}_{50}$ values (Table 1), the ripe extract had a significantly higher $(\mathrm{P}<0.05)$ DPPH $(2.95 \pm 0.04 \mu \mathrm{g} / \mathrm{ml})$ scavenging abilities, when compared to the unripe extract
$(3.81 \pm 0.02 \mu \mathrm{g} / \mathrm{ml})$; however, the unripe extract $(131.8 \pm 0.04 \mu \mathrm{g} / \mathrm{ml})$ had a significantly higher $(\mathrm{P}<0.05) \mathrm{OH}$ radical scavenging ability compared to the ripe extract $(219.0 \pm 0.03 \mu \mathrm{g} / \mathrm{ml})$.

Concentrations of total phenol, total flavonoid and non-flavonoid contents in C. frutescens extracts are presented in table 2. The ripe fruit had significantly higher $(\mathrm{P}<0.05)$ total phenol

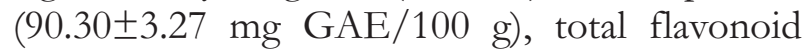
(66.67 $\pm 7.86 \mathrm{mgQAE} / 100 \mathrm{~g}$ ) than the unripe fruit (total phenol $=86.04 \pm 4.16 \mathrm{mgGAE} / 100 \mathrm{~g}$; total flavonoid $=52.10 \pm 0.09 \mathrm{mgQAE} / 100 \mathrm{~g}$ ). However, the unripe fruit had higher content of non-flavonoid phenol contents $(33.94 \pm 4.16$ $\mathrm{mg} / 100 \mathrm{~g})$ than the ripe fruit $(23.63 \pm 11.13$ $\mathrm{mg} / 100 \mathrm{~g})$. 


\section{DISCUSSION}

Central to the pathology of Parkinson's disease (PD) is the loss of doparminergic neuron at the substantial nigra pars compacta (SNpc) region of the brain (Hauser and Hastings, 2013). This loss of dopaminergic neurons consequently leads to depletion of the neurotransmitter-dopamine (DA) resulting in the characteristic symptoms of PD. One of the reasons for loss of DA is the elevated activity of monoamine oxidase (MAO), which catalyses the oxidation of monoamines such as DA (Hauser and Hastings, 2013). Therefore, one therapeutic strategy for the management of PD is to retard DA oxidation by reducing the activity of $\mathrm{MAO}$ via its inhibitors. Consequently, the ability of $C$. frutescens to inhibit the activities of mitochondria MAO activity could be a positive step in serving as a functional food/nutraceutical therapy in the prevention/management of $\mathrm{PD}$; a bioactivity which could probably be attributed to their constituent polyphenols. The therapeutic potentials of plant phenolic extracts for the management of PD by inhibiting MAO activities (in vitro) has been reported; in one study, Nwaana et al. (2016) reported the MAO inhibitory effect of some commonly consumed green leafy vegetables in southern Nigeria, while Lee et al. (2000) has also shown the inhibitory effect of phenolics from Mugwort on mouse brain monoamine oxidase activity.

In the aetiology of neurodegenerative disorders, oxidative stress is regarded both as a causative factor and a resultant condition which leads to loss of neurons (Uttara et al., 2009; Chen et al., 2012; Neidzielska et al., 2016). In PD, elevated MAO activities are often accompanied by excessive free radical generation which ultimately results in oxidative stress (Hauser and Hastings, 2013). As such antioxidant therapies particularly from the diet are considered as critical to effective PD management. Interestingly, the phenolic extracts from $C$. frutescens showed significant antioxidant properties, including DPPH free radical scavenging ability as well as ability to quench the Fenton reaction by scavenging $\mathrm{OH}$ radicals. These could therefore, be of therapeutic importance in arresting PD-induced oxidative stress in neuronal cells. This study agrees with previous findings on the antioxidant properties of plant phenolic extracts especially as potential dietary therapeutic measures in the management of neurodegenerative diseases (Yilmaz et al., 2013).

The cholinergic hypothesis of dementia supports the view that elevated activity of acetylcholinesterase is implicative in dementia processes and the use of AChE inhibitors have been able to slow down the progression of dermatan in AD and PD patients. Therefore, in this study, the ability of the phenolic extracts of $C$. frutescens to inhibit the activities of both $\mathrm{AChE}$ and $\mathrm{BChE}$ could be of therapeutic significance in the management of PD-associated dementia. The ability of plant phenolic extracts to inhibit cholinesterase activities in vitro has been well reported; Oboh et al. (2016) reported the cholinesterase inhibitory effect of phenolic extracts from Heinsia crinita leaves with potential neuroprotective properties, while GironésVilaplana et al. (2012) reported the anticholinesterase properties of a blend of black chokeberry and lemon juice as a dietary intervention for the management of neurodegenerative diseases such as PD and AD attributing the enzyme inhibitory properties of this blend of juice to their constituent phytochemicals which is rich in flavonoids. This study also agrees with that of Oboh et al. (2015) on the ability of two varieties of tomato to show potential neuroprotective properties via their anticholinesterase and antioxidant effects.

The membrane stabilizing properties of the extracts is also noteworthy, as both extracts were able to inhibit lipid peroxidation induced by $\mathrm{Fe}^{2+}$ in rat brain tissue homogenate. The ability of the extracts to inhibit the lipid peroxidation chain reaction could be as a result of their ability to scavenge $\mathrm{OH}$ free radicals and thus attenuate the Fenton reaction processes. Peroxidation of membrane lipids is a consequence of the high generation of ROS in neuronal cells of PD. There is high generation of ROS in mitochondrial of PD subjects which often overwhelms the antioxidant defence status and thus, resulting in oxidative damages of macromolecules. Hence, the ability of the extracts to inhibit lipid peroxidation and offer membrane stabilizing potentials could be another mechanism supporting their therapeutic potentials in the management of PD and other 
neurodegenerative diseases. These neuroprotective potentials could be ascribed to the presence of the phytochemicals present in the fruits.

In conclusion, this study has been able to show that phenolic extracts from ripe and unripe pepper (C. frutescens) fruits were able to inhibit the activities of rat brain cholinesterases and mitochondria MAO activities in vitro. The extracts also exhibited antioxidant properties by scavenging DPPH and $\mathrm{OH}$ radicals, as well as exhibit membrane stabilizing properties by inhibiting $\mathrm{Fe}^{2+}$ induced lipid peroxidation in rat brain tissue. These observed bioactivities could probably be attributed to their constituent phenolic phytochemicals and could help explain at least in part the mechanisms to justify the use of $C$. frutescens fruits as potential nutraceutical interventions in the prevention/management of neurodegenerative diseases such as PD.

\section{REFERENCES}

Akinyemi,, A. J., Thome, G. R., Morsch, V. M., Stefanello, N., da Costa, P., Cardoso, A. and Schetinger, M. R. C. (2016). Effect of dietary supplementation of ginger and turmeric rhizomes on ectonucleotidases, a denosine deaminase and acetylcholinesterase activities in synaptosomes from the cerebral cortex of hypertensive rats. Journal of Applied Biomedicine 14: 59-70.

Angeline, M. S., Chaterjee, P., Anand, K., Ambasta, R. K. and Kumar, P. (2012). RotenoneInduced parkinsonism elicits behavioral impairments and differential expression of parkin, heat shock proteins and caspases in the rat. Neuroscience 220: 291301.

Belle, N. A. V., Dalmolin, G. D., Fonini, G., Rubim, M. A. and Rocha, J. B. T. (2004). Polyamines reduce lipid peroxidation induced by different prooxidant agents. Brain Research 1008: 245-251.

Chen, X., Guo, C. and Kong, J. (2012). Oxidative stress in neurodegenerative diseases. Neural Regeneration Research 7(5): 376-385

Cookson, M. R. and Bandmann, O. (2010). Parkinson's disease: insights from pathways. Human Molecular Genetics 19:
R21-R27.

Ellman, G. L., Courtney, K. D. and Featherstone, R. M. (1961). A new and rapid colorimetric determination od acetylcholinesterase activity. Biochemical Pharmacology 7:88-95.

Gacche, R. N., Shaikh, R. U., Chapole, S. M., Jadhav, A. D. and Jadhav, S. G. (2011). Kinetics of inhibition of monoamine oxidase using Cymbopogon martini (Roxb.): A potential antidepressant herbal ingredient with antioxidant activity. Indian Journal of Clinical Biochemistry 26:303-308.

Gironés-Vilaplana, A., Valentão, P., Andrade, P. B., Ferreres, F., Moreno, D. A. and GarcíaViguera, C. (2012). Phytochemical profile of a blend of black chokeberry and lemon juice with cholinesterase inhibitory effect and antioxidant potential. Food Chemistry 134:2090-2096.

Green, A. L. and Haughton, T. M. (1961). A colorimetric method for the estimation of monoamine oxidase. Biochemical Journal 78:172

Gyamfi, M., Yonamine, M. and Aniya, Y. (1999). Free-radical scavenging action of medicinal herbs from Ghana, Thonningia sanguinea on experimentally-induced liver injuries. GeneralPharmacology 32:661-667.

Halliwell, B. and Gutteridge, J. M.C. (1981). Formation of a thiobarbituric-acid reactive substance from deoxyribose in the presence of iron salts: the role of superoxide and hydroxyl radicals. FEBS Letters 128:347-352.

Hauser, D. N. and Hastings, T. G. (2013). Mitochondrial dysfunction and oxidative stress in Parkinson's disease and monogenic parkinsonism. Neurobiology of Disease 51:35-42.

Jolayemi, A. T. and Ojewole, J. A. O. (2013). Comparative anti-inflammatory properties of Capsaicin and ethylaAcetate extract of Capsicum frutescens linn [Solanaceae] in rats. African Health Sciences 13:357-361.

Khan, I., Ahmad, H. and Ahmad, B. (2013). Antiglycation and Anti-oxidation properties of Capsicum frutescens and Curcuma longa fruits: Possible role in prevention of diabetic complication. Pakistan Journal of 
Pharmcentical Sciences 27:1359-1362.

Lee, S. J., Chung, H. Y., Lee, I. K., Oh, S. U. and Yoo, I. D. (2000). Phenolics with inhibitory activity on mouse brain monoamine oxidase (MAO) from whole parts of Artemisia vulgaris L (Mugwort). Food Science and Biotechnology 9:179-182.

Lowry, O. H., Rosenbrough, N. J., Farr, A. L. and Randoll, J. (1951). Protein measurement with the Folin phenol reagent. Journal of Bioological Chemistry 193: 265-75.

Meda, A., Lamien, C. E., Romito, M., Millogo, J. and Nacoulma, O. G. (2005). Determination of the total phenolic, flavonoid and praline contents in Burkina Faso honey, as well as their radical scavenging activity. Food Chemistry 91:571-577.

Moore, D. J., West, A. B., Dawson, V. L. and Dawson, T. M. (2005). Molecular pathophysiology of Parkinson's disease. Annual Review of Neuroscience. 28:57-87.

Niedzielska, E., Smaga, I., Gawlick, M., Moniczewski, A., Stankowicz, P., Pera, J. and Filip, M. (2016). Oxidative stress in neurodegenerative diseases. Molecular Neurobiology 53(6): 4094-4125

Nwanna, E. E., Oyeleye, S. I., Ogunsuyi, O. B., Oboh, G., Boligon, A. A. and Athayde, M. L. (2016). In vitro neuroprotective properties of some commonly consumed green leafy vegetables in Southern Nigeria. NFS Journal 2:19-24.

Oboh, G. and Ogunruku, O. O. (2010). Cyclophosphamide-induced oxidative stress in brain: Protective effect of hot short pepper (Capsicum frutescens L. var. abbreviatum). Experimental and Toxicologic Pathology 62:227-233

Oboh, G., Bakare, O. O., Ademosun, A. O., Akinyemi, A. J. and Olasehinde, T. A. (2015). Inhibition of cholinesterases and some pro-oxidant induced oxidative stress in rats brain by two tomato (Lycopersicon esculentum) varieties. International Journal of Biomedical Science 11:48.

Oboh, G., Nwanna, E. E., Oyeleye, S. I., Olasehinde, T. A., Ogunsuyi, O. B. and Boligon A. A. (2016). In vitro neuroprotective potentials of aqueous and methanol extracts from Heinsia crinita leaves. Food Science and Human Wellness 5:95102.

Ohkawa, H., Ohishi, N. and Yagi, K. (1979). Assay for lipid peroxides in animal tissues by thiobarbituric acid reaction. Analytical Biochemistry 95:351-358.

Satav, J. G. and Katyare, S. S. (1982). Effect of experimental thyrotoxicosis on oxidative phosphorylation in rat liver, kidney and brain mitochondria. Molecular and Cellular Endocrinology 28: 173-189

Singleton, V. L., Orthofer, R. and Lamuela-

Ravent'os, R. M. (1999). Analysis of total phenols and other oxidation substrates and antioxidants by means of folinciocalteu reagent. Methods in Ensymology 299:152- 178.

Sloley, B. D., Urichuk, L. J., Morley, P., Durkin, J., Shan, J. J., Pang, P. K. T. and Coutts, R. T. (2000). Identification of kaempferol as a monoamine oxidase inhibitor and potential neuroprotectant in extracts of Ginkgo biloba leaves. Journal of Pharmacy and Pharmacology 52:451-459.

Soldner, F., Hockemeyer, D., Beard, C., Gao, Q., Bell, G. W., Cook, E. G., Hargus, G., Blak, A., Cooper, O., Mitalipova, M., Isacson, O. and Jaenisch, R. (2009). Parkinson's disease patient-derived induced pluripotent stem cells free of viral reprogramming factors. Cell136:964-977.

Tamilselvam, K., Braidy, N., Manivasagam, T., Essa, M. M., Prasad, N. R., Karthikeyan, S. et al (2013). Neuroprotective effects of hesperidin, a plant flavanone, on rotenone-induced oxidative stress and apoptosis in a cellular model for Parkinson's disease. Oxidative Medicine and Cellular Longevity doi: 10.1155 /2013/102741

Uttara, B., Singh, A. V., Zamboni, P. and Mahajan, R. T. (2009). Oxidative stress and neurodegenerative diseases: A review of upstream and downstream antioxidant therapeutic options. Current Neuropharmacology 7(1): 65-74

Yllmaz, B. S., Altun, M. L., Orhan, I. E., Ergene, B. and Citoglu, G. S. (2013). Enzyme inhibitory and antioxidant activities of Viburnum tinus L. relevant to its neuroprotective potential. Food Chemistry 141:582-588. 